\title{
Rudimentos de salud pública para no especialistas: entendamos mejor la pandemia de COVID-19
}

\author{
Luis Guerra Romero \\ Exdirector de la Fundación de Investigación del Hospital Ramón y Cajal, Exdirector de la Escuela Nacional \\ de Sanidad (lnstituto de Salud Carlos III); Médico jubilado; luisguerom@gmail.com; https://orcid.org/0000- \\ 0003-0063-5877
}

DOI: https://doi.org/10.37536/RIECS.2020.5.1.205

Recientemente he publicado un artículo de divulgación, con el título arriba mencionado, en la web de la Escuela Andaluza de Salud Pública, que dada su extensión se ha dividido en dos partes, parte I https://www.easp.es/web/coronavirusysaludpublica/rudimentos-de-salud-publica-para-noespecialistas-entendamos-mejor-la-pandemia-de-covid-19-i/ $\quad$ y $\quad$ parte $\quad$ II https://www.easp.es/web/coronavirusysaludpublica/rudimentos-de-salud-publica-para-noespecialistas-entendamos-mejor-la-pandemia-de-covid-19-ii/

El artículo trata de recoger de una manera didáctica los elementos fundamentales de las medidas de control de las epidemias. Quiere ser una ayuda para entender mejor la actual pandemia de COVID-19, orientada a personas interesadas en este tema que no son profesionales sanitarios.

El artículo se inicia con una sucinta revisión del contexto histórico de las epidemias, que se puede dividir en antes y después del conocimiento del origen microbiano de las enfermedades infecciosas, en definitiva, de la aparición de la "teoría del germen". Introduce ya algunos términos y aporta algunas lecciones aprendidas del pasado. Continúa con la propuesta de los elementos esenciales para el control de las epidemias, tratando de hacer énfasis en que el problema no es solo debido a la irrupción de una infección determinada, con sus peculiaridades biológicas y médicas. Las epidemias se combaten con unos sistemas sanitarios que con mayor o menos éxito las doblegan. Además, hay que considerar que se desarrollan en sociedades muy distintas, cuyas características condicionan el éxito o fracaso de su control. Por último, se incide en los contextos sociales con varios ejemplos paradigmáticos de epidemias y en el epílogo se explicita que se ha evitado hacer una elaboración detallada de los aciertos y errores de la gestión de la pandemia actual.

Esto, por una parte, requeriría otro artículo para hacerlo a un nivel de divulgación con un mínimo de rigor y por otra, se estima que un lector atento podría hacerlo por su cuenta. Se hace explícito que estamos empezando a salir del momento más desalentador de la pandemia de COVID19 en España y que no es éste el momento más apropiado para hacer críticas, muy fáciles a posteriori y sin disponer de una información suficiente para hacerlas con rigor. En breve, se podrá hacer una crítica constructiva con el fin de aprender las lecciones clave para el futuro.

(C) 2020 por los autores; Esta obra está sujeta a la licencia de Reconocimiento 4.0 Internacional de Creative Commons. Para ver una copia de esta licencia, visite http://creativecommons.org/licenses/by-nc-nd/4.0/. 